\title{
Female Leaders and Work-life Balance within the Hotel Industry: A conceptual Approach
}

\author{
May Aly Fouad Elariny ${ }^{1}$,Ayman H. Metwally ${ }^{1}$, Sherif H. Hassan ${ }^{1}$ \\ and Yehia Sabri Nawar ${ }^{2}$
}

\author{
${ }^{1}$ Arab Academy for Science and Technology and Maritime Transport, College of \\ Management and Technology, Alexandria, Egypt \\ ${ }^{2}$ Business and Management, London South Bank/ University of west London
}

\begin{abstract}
Many countries have made progress towards gender equality over the past two decades, but significant gaps persist in workforce participation, leadership positions and barriers face by employees. Major disruptions in the labor market have begun that could have profound implications for gender equality through 2030. Automation and artificial intelligence, for example, will displace many workers while, simultaneously, increasing investments, rising incomes or ageing population trends will create new jobs that require skills in short supply. Leadership is a management function, which is mostly directed towards people, it's a process of influencing people to achieve the goals of the organization. The academic importance of this research is to offer bases by which researchers can have access to measure female leadership, work life balance and their relation to financial performance in developing countries. This research will increase the available literature on the topic specifically on developing countries such as the Egyptian corporate sector; in addition to the literature on the effect of work- life balance and female leadership financial performance relation. Furthermore, demographic variables are tested to assess their effect on the independent dependent relation.
\end{abstract}

Keywords: Female, Leadership. Work Life Balance, Hotel industry, Conceptual Paper.

\section{Introduction}

Many years of research generated a platform of findings, yet the overwhelming accumulation of empirical data has not culminated into a unified understanding of gender and its relation to leadership style and organization success. These disparate perspectives have limited the focus of most researchers, which is compounded by the paucity of broad theories to integrate findings from the alternate approaches. There is a wide debate in leadership definitions, by which since 1930s there are multiple emerging theories and definitions; however, there was no consensus on a single one (1). Thus the mata analysis found over 850 definitions in leadership literature .Hence attributed leadership as an act that takes place inside organizations, families or groups of friends ; such act either is carried and defined by a power structure or without clearly managerial power. Leadership as described by (2) is the capacity of a character to persuade, encourage and permit others to contribute to the effectiveness and achievement of the agency that they are contributors of, as a result it was concluded that the leaders role is of maximum importance in directing organizational performance. (3). There are several types of leaders; a leader is seen through position, personality, charisma, moral, power or intellectual capacity. Thus Opstrup and Villdsen (2)defined leaders as people who earn their power through their followers willingness to follow them.

\section{Female Leadership}

\subsection{The Business Case}

The business case for diversity holds that group diversity is a primary supporter for performance enhancement (5).Accordingly, the cognitive recourse model proposes that as (gender) diversity in teams expands, the accessible intellectual assets increases (6)If utilized adequately, it will contribute to a more thorough search for alternative solutions to problems because they introduce new perspectives to the boardroom (8)These differing points of view likewise encourage a basic examination of complex issues, forestall untimely dynamic, and create inventive and imaginative arrangements (9)Hence, expanded female presence on corporate positions and 
board of directors ought to improve firm financial performance through the assorted points of view acquainted with in the meeting room. Another view on the side of the business case for diversity is that women present valuable female leadership characteristics, styles and aptitudes to the meeting room. What's more, female leaders satisfy their leadership jobs in a more transformational style than their male partners, separating themselves particularly through their empowering, encouraging and supportive treatment of associates and subordinates. An expanded female presence in terms of aptitudes, presents an assortment of key points of interest for organizations. Following this thinking, a positive connection between expanded female presence and firm financial performance is argued.

Leadership is a vast topic by which several theories and leadership styles are present; female leadership is a part of such concept, female leadership is defined in several ways and viewpoints (Lahti 2013).Leadership theories are attributed to being gender neutral (Fletcher, 2004). However recently studies have shed light on how gender and personality could affect the leader personality and style, thus affecting the overall performance of the organization (Anselmo , 2018). In most cases female leadership is perceived as either the females right of equal opportunities as its male counterpart or the female's ability of presence in the board of directors (Palmu-joronen 2009). Each gender has its set of unique qualities, attributes and traits thus having different realties and ways to understand the world (Vinnicombe and Singh, 2002).

\subsection{Female leadership theories}

Leadership literature highlights several unique theoretical perspectives posited to justify the existence of a difference between male and female leaders. Despite these alternate perspectives, which provided a blueprint for conducting research on gender, leadership style, and organizational outcomes, transformational, transactional, and contingency theories of leadership undergird the proposed study. According to Boykins, Campbell, Moore, and(7), these three theories underpin effective leadership styles prevalent in most organizations.

Burns (1978) first featured transformational and transactional leadership styles as being on opposing ends of the leadership continuum. He contended that a leader exhibits only one distinct style of leadership. According to this perspective, transformational leaders approach their subordinates with the aim of altering their values, beliefs, and needs; motivating them to perform beyond their own expectation. Transactional leaders on the other hand identify the actions required by followers to achieve the required

\section{ISSN 2455-6378}

task or expected outcome and they facilitate that action (Burns, 1978). According to the alternate theories, transformational leaders are focused on ensuring that followers are inspired to transcend organizational expectations, while transactional leaders are contented with ensuring that followers comply with the established performance structure that is essentially contingent upon reward and exchange.

Bass (1985) expanded these views and presented a more comprehensive perspective of transformational and transactional leadership by incorporating the constructs of task orientation and relationship orientation. He postulated a pristine leadership paradigm where transactional and transformational leadership were not perceived as being on a single continuum, but rather autonomous, and synergies would yield greater effectiveness. Within this context, the adoption of transactional style to secure low-order objectives could be complemented with transformational style to effect high-order changes, essentially optimizing organization performance (Bass, 1990).

Contingency theorists posit that leadership behavior is typically contextual, and that the effectiveness of a leader is contingent on the characteristics of the situation, with experience and realities interceding and driving behaviors (Fielder, 1967). The proponents of this theoretical perspective contend that there is no single best way to lead. Moreover, organization structure as well as that of their subsystems must be tailored to suit the existing environment. This theory suggests that the effectiveness of a leader is contingent on their particular leadership style and its interaction with aspects of the situation (Bass, 1990). They suggest that men and women are groomed by societal and cultural norms to embrace a behavioral style in tandem with society's expectations of how they should behave. Consequently, female leaders adopt more conciliatory, relationship oriented behaviors, as these are congruent with societal expectations.

\subsection{Leadership style characteristics}

Gender impacts leadership style - female leaders in top management engage in a more transformational while their male counterparts engage in a more transactional leadership style.( Oakley, 2000 ). Thus 'Sex differences in leadership examine how females and males leaders actually differ in attitudes, values, skills, behaviors and effectiveness "' (Anselmo, 2018). Early theories on leadership, described men as leaders while women were deliberately excluded as they were perceived as having distinctively different behaviors, skills, and attitudes that impeded their progression in management (Ester et.al , 2018). These theories emphasized the importance bestowed 
on male characteristics or traits in leadership (Khurram, 2019). Great Man Theory for example hypothesized that a true leader is born and not made (Anselmo, 2018) and talent, character, competency, purpose, values, and expertise as forming the basis of effective leadership (Miranda , 2019). Women were in no way perceived as possessing the qualities to be a leader. Trait theory, which bears close association with great man theory, posited that certain personality traits and individualistic characteristics enhance the propensity of a person to be an effective leader. This theory emphasizes the traits of a man, as being pertinent in achieving success as a leader. This characteristic or trait was later validated by Schein (1973) in his work that described the "Think Manager - Think Male" phenomenon. He declared that managers who were successful possessed attitudes, characteristics, and a temperament congruently aligned with males rather than females.

Role congruity theory espoused by Eagly (1987) suggested that people promote a descriptive gender role expectation of individual behavior grounded in the concept of a sex-based division of labor, which has traditionally identified men as the provider and women as the one who manages the home (Koenig \& Eagly, 2014).Consequently, the expectation that women are more communal, relationship-oriented, and nurturing, while men were assertive and independent were predicated on these social roles. Eagly and Johnson (1990) also conducted a metaanalysis of three types of research and concluded that women employ a more democratic and participative style of leadership, compared with their male counterparts who typically adopt an autocratic and task-oriented style in organizational settings. These agentic characteristics typically identified with men are found to be congruent with the traditional stereotypes of female leaders (Schein, 1973). Other earlier studies asserted that women leaders were comparatively more supporting, appreciative, caring, compassionate, socially sensitive, and amenable than their male counterparts. Burns (1978) referred to a robust element of "developmentalism" in transformational leadership. He contended that transformational leaders place a significant emphasis on distinguishing among the many demands of their members and seek to understand these needs while assisting them in achieving their goals. According to Burns (1978), this component of "developmentalism" is relatively easy to accomplish in women since they are characterized as being more considerate, caring, and willing to listen. As researchers began to question the adequacy of a person's traits as being the sole determinant of leadership effectiveness other situational factors were considered. The deliberate elimination of gender as a variable in leadership was perceived as creating major gaps in theoretical and research design. According to Ababneh, and Athamneh,

\section{ISSN 2455-6378}

(2018) this led to a shift away from the possession of a set of universal characteristics to a new conceptualization of leadership, ultimately ushering in the evolution of new theories, which provided a comprehensive understanding of the dynamics of a leader. Contemporary theories have served to foster a heightened recognition of women's contribution as leaders. While recent research still provides disparate conclusions on gender and leadership, it emphasizes more gender homogeneity than heterogeneity. Some researchers have insisted that there are no notable gender differences in leader decision-making, values, or styles Other researchers concluded that men and women leaders exhibit significantly more similarities than differences in managerial traits (Walker, \& Woehr, 2014). There are other studies that concluded male and female leaders attain the same level of success in the decision-making process under conditions of uncertainty and achieve equal success in their roles as leaders by possessing the same level of competence when processing and reacting to information (Nicolas et.al, 2020).

\subsection{Work Life Balance}

Since 2000s work life balance (WLB) became one of the most researched topics in human resource management (Bento et al 2015). Such trend is attributed to demographic, cultural and economic changes such as the increase in female representation in the labor market (Lazar and Ratiu, 2009). Phillips and Prieto (2016) defined work life balance " as the organizational human resource policies or programs that help employees to manage the interface between work and family responsibility'. As there is an increase in work related stressors, and hence the need for work life balance became a necessity for employees especially females who reach top level management, they need to boarder line there personal life and work related life (Phillips and Prieto , 2016). Work life balance is defined as the assumption that an employee's personal life shouldn't be competing with his/ her work life , thus they come as hand-in- hand complimentary parts ( Akanji , Mordi , Ojo , 2015) . Therefor it is defined by (Adame et.al, 2016) as "'satisfaction and good functioning at work and at home, with minimum role conflict". Hence, in Literature "work" is seen in terms of employment or activities that yield a salary/ wage, while anything outside an employment base is the "'life" thus to reach WLB an "equilibrium ", balance between both worlds should be present so as they don't conflict or collide ( Akanji , Mordi , Ojo , 2015) . Several organizational practices aim towards work life balance such as work family facilitation, enrichment, part- time work, job sharing, career break, compressed work hours etc. whereby employee work life should benefit an employee's family life and overcome the conflict between 
demands (Harrison and Wagner, 2016). Such conflict reduces the employee's productivity and negatively affects the firm's performance (Wood et.al , 2020). The main aim through WLB practices in an organization is to support and aid employees in overcoming work juggling and role conflict (Murphy and Doherty ,2011).WLB as a notion is a derived from two main theories, first of those theories is the attitude behavior theory which suggests that an employee's perception of the work place affects his performance therefor when organizations implement WLB according to theory the employee will perceive the organization as supportive and hence exert higher effort and better performance (Fishbein and Ajzen ,1975).

\section{Proposed Conceptual Framework}

Previous studies on the relation between female leadership and financial performance.

\begin{tabular}{|l|l|}
\hline Female leadership & $\begin{array}{c}\text { Financial } \\
\text { performance }\end{array}$ \\
\cline { 2 - 3 } &
\end{tabular}

Existing literature over gender diversity and firm performance is interdisciplinary. The research has combined various academic fields such as, corporate governance, management, finance, law, leadership, sociology and even entrepreneurship. Studies have been conducted on micro and macro levelsindividual, board, firm and industry. The perspectives at the individual level are human and social capital theories as well as gender schema. The predominant perspectives at board level are social networks and social identity as well as critical and political theories at industry level. Following are several studies that provided an insight on the relation between female leadership and the financial performance.

Research hypothesis According to Brian Moskal (1997), because of their leadership style, women executives excell primarily as team players in corporate America. It also mentions that males primarily excell in left-brain activities such as problem-solving, whereas females primarily excel in right-brain activities such as interpersonal relations. The findings of these studies show that the thought processes of workers and the aspirations of leaders differ across the class. It is also safe to assume that leadership is closely related to the style of transformation. Ocak and Ozturk (2018) were thus hypothesizing a positive relationship between transformative leadership (Brian Moskal attributed 1997 as the style most followed by women(and the financial performance, by which Transformational leadership behaviours of managers have a significant impact on the financial performance of organizations Ocak and Ozturk (2018).

\section{ISSN 2455-6378}

Konrad (2014) have indicated in their research into the female leadership framework of top management that the proportion of female directors has a positive effect on firm performance. This research has been carried out on 679 Fortune 1,000 companies registered since 1998 and has had a major impact on future career women. Smith et al . (2006) researched 2,500 companies in Denmark and the result showed that a more gender-based board could also improve the competitive advantage and corporate image of a company and have a positive effect on customer behaviour. Francoeur et al . ( 2006) conducted research in Canada and found empirical evidence that having a higher proportion of women produces positive and significant abnormal returns. Ibarra and Obodaru (2009) in the Harvard Business Review reported that women's top management efficiency was higher than men's. This research was carried out using a 360-degree evaluation of the Executive Development Program at INSEAD. Miller and Triana (2009) have indicated that women will increase firm performance. Post and Byron (2015) combined 140 studies that examined the empirical evidence that a female director was positive for the firm's performance. Dezso and Ross (2012) indicated that female representation in top management would enhance the board's information and social diversity, which could bring benefits to management, enhance managerial behavior and motivate women in middle management. Women's representation remains, therefore, an important indicator of the success of firms. Thus $(11 ; 12 ; 13 ; 14 ; 15)$, have shown that a female director is of positive significance for the company's performance.

\section{Findings and Discussion}

One reason for the increased interests in female leadership is that historically women have been, and continue to be, under-represented in senior corporate leadership roles $(11 ; 12 ; 13 ; 14 ; 15)$. However the previous studies explaining the relationship between female leadership and financial performance discussed in most of these studies examined the impact of women directors as being a gender rather than their personalities or behavior on only one measure of corporate performance $(10 ; 110$

In a recent critique, nawar (13) defined three main concerns that should be solved before reaching conclusion about the relation between female leadership and financial performance. First, there is a lack of the rigorous scientific findings, second, the glass-ceiling-breaking facing women in leadership positions. And Finally, she argues that it causal inferences from studies that attempt to relate the gender composition of boards to firm performance would not be applied to all scenarios. As this relationship may be confounded by a number of 
unmeasured factors such as the personality, styles or barriers faced.

\section{Conclusions}

The primary objective of this study is to explore the effect of female leadership and work life balance on firm financial performance. Additionally, a review of the female leadership literature reveals three attributes that can affect the financial performance of firms. These attributes being: transformational leadership, stereotyping effect and the glass ceiling. These attributes are selected based on theories and the prior literature to be effective in explaining the business case which is the main concern, given that the study is based upon the female leadership and its implications. The empirical examination of the hypotheses developed from the conceptual framework presented in this study female leadership factors and work life balance on firm financial performance. Consistent with prior research the study uses transformational leadership, stereotyping effect and the glass ceiling as previously measured in previous studies. The study computes financial performance in terms of ROE and ROA. The research results, findings and detailed analyses of the empirical study were presented in the following manner. The descriptive statistics were used to describe the data and then regression was conducted to show the direction and strength between female leadership, work life balance and Firm financial performance.

Based on the mentioned limitations, a few recommendations are presented for future research in the same topic of interest. It is recommended that future studies can focus on other theories of leadership, covering other factors of female leadership and work life balance. This will help have a broader and more general picture on the topic of female leadership. The final suggested model might help as a base for future studies, since it presents a new classification of female leadership variables and dimensions.

\section{References}

(1)Ababneh, Raed \& Athamneh, Seif. (2018); Women's Leadership Styles and Followers; Commitment: The Case of the Jordanian Public Sector. The International Journal of Organizational Diversity. 18.

(2)Abdullah SN, Ku Ismail KNI. 2014. Gender, ethnic and age diversity and performance of large
(3)Abdullatif, Modar \& Mohmmad, Suleiman \& Zakzouk, Fida. (2018). The effect of gender diversity on the financial performance of Jordanian banks. Academy of Accounting and Financial Studies Journal. 22.

(4)Adame, C., Caplliure, E., \& Miquel, M. (2016). WLB and firms: A matter of women? Journal of Business Research,

(5)Adams, Renee \& Funk, Patricia. (2012). Beyond the Glass Ceiling: Does Gender Matter?. Working Papers ( Universitat Pompeu Fabra. Departamento de Economía y Empresa )

(6)Adler, Nancy. (2007). One world: Women leading and managing worldwide. Handbook on Women in Business and Management. 330-355.

(7)Akanji, B.O., Mordi, C., \& Ojo, S.I. (2015). Reviewing Gaps in Work-Life Research and Prospecting Conceptual Advancement.

(8)Alas, R., \& Mousa, M. (2016). Organizational culture and workplace spirituality. International journal of emerging research in management and technology, 5(3)

(9)Alimo-Metcalfe, B., \& Alban-Metcalfe, J. (2003) 'Leadership: A Male Past, But a Female Future?' Proceedings of the British Psychological Society Occupational Psychology Conference. Bournemouth, January 2003, 67-70.

(10)Nabih, Y, Metwally, AH \& Nawar Y.S. (2016). "Emotional Intelligence as a Predictor of Leadership Effectiveness" The Business and Management Review 7 (5), 133-142.

(11)Nawar, Y.S. (2015). "Organizational Commitment: As a Mediator on the Relationships between Leadership Styles and Job Satisfaction in New Emerging Economy". International Journal of Management and Commerce Innovations, 2(4) 44.54.

(12)Nawar. S., Nazarian, A. \& Hafez, K. (2015). "The Influence of Strategic Planning and organizational culture on Leadership-Performance Relationship. The Case of Egyptian Private SME'S". British Academy of Management Conference. (September 2015, Portsmouth, UK).

(13)Riad, L., Labib, A\& Nawar Y.S. (2016). "Assessing the Impact of Organisational Climate on Employees Commitment" The Business and Management Review 7 (5), 357-364

(14)Rigas, D. \& Nawar, Y.S (2016). "Leadership and Innovation Growth: A Strategic Planning andOrganizational Culture Perspective". International Conference on HCI in Business, Government and Organizations pp. 565-575.

(15)Samara, R.M. \& Nawar, Y.S. (2015). “Assessing the Impact of Strategies Formulation and Implementation on Londoners' Local Communities Satisfaction. "The Case of London Heathrow Airport". International Journal of Scientific and $\begin{array}{llll}\text { Technology Research } 3 & \text { (4), 16-28. }\end{array}$ 